\title{
Medical paternalism and the fetus
}

John Wyatt University College, London

\begin{abstract}
A number of developments in the medical field have changed the debate about the ethics of abortion. These developments include: advances in fetal physiology, the increase in neonatal intensive care and the survival rates of premature infants. This paper discusses the idea of selective termination and the effects that these decisions have on disabled people of today. It presents a critique of the counselling services that are provided for the parents of a disabled fetus and discusses how this is viewed from a social perspective. The article ends with an argument that the mother deserves to be autonomous in the decision of abortion. The easiest and most fair way to develop her autonomy is to consider the relationship between a professional and a mother as an expert-expert relationship. Here both parties are considered experts in diagnostic

information, treatment options, possibilities, and their history, family roots, philosophy and way of life, respectively.

(Fournal of Medical Ethics 2001;27 supp1 II:ii15-ii20)
\end{abstract}

Keywords: Abortion; paternalism; fetus; disability; autonomy; feticide

In the continuing debate about the ethics of abortion, it is vital that we recognise our differing vantage points. I am writing from a particular perspective: that of a neonatologist in a major perinatal centre. My professional responsibilities include the intensive care of critically ill and very preterm babies, liasing with obstetricians and fetal medicine specialists in the management of complex fetal illnesses, and counselling pregnant women and their partners who are considering the option of abortion or late feticide for "medical reasons".

In this paper I wish to outline five developments that seem to me to have irreversibly changed the ongoing ethical debate about abortion. I will then address the issues of medical paternalism and medical duties to the fetus, and suggest an alternative model for professional-patient relationships.

\section{Advances in fetal physiology}

In 1967 when the Abortion Act came into force in Britain, the scientific understanding of fetal development and behaviour was rudimentary. The fetus was shrouded in mystery. Even newborn babies were thought to be incapable of any sophisticated perceptual or learning abilities. As a medical student, I was taught that newborn babies were blind, unaware of their surroundings and incapable of feeling pain. Twenty years later we have discovered that babies have a range of sophisticated abilities with well developed sensory perception in all systems: vision, hearing, touch, taste and smell. They also have a wide range of learning capacities (including even the ability to imitate facial expressions). In view of this surprising sophistication of behaviour, questions were then raised about the stage of antenatal life at which these complex responses commenced. The development of ultrasound imaging has transformed the study of fetal physiology and behaviour. With modern equipment extraordinary detail, including rapid eye movements, breathing activity, fine motor patterns and cardiovascular responses can all be recorded and analysed. The first fetal movements are seen at seven weeks and over 20 different movement patterns have been described up to 16 weeks including hand-face contact, startle and sucking and swallowing movements. During the second trimester rest-activity cycles are observed and the development of rapid eye movement (REM) periods starts at 23 weeks. During the last three to four weeks complex and stable patterns of behaviour are apparent.

The fetus first responds to sound at 20 weeks and subsequently develops more sophisticated auditory processing with the ability to discriminate different sounds. Towards the end of pregnancy the mother's voice can apparently be perceived clearly through the other sounds of the abdomen. Other responses include those to touch, changes in temperature and even the taste of the amniotic fluid. The newborn recognises its mother's smell and the taste of the breast milk immediately after birth. From 25 weeks the fetus tries to maintain its position in space, as the mother moves around. Complex cardiovascular and hormonal stress responses to invasive procedures have been detected from before 20 weeks gestation and there is continuing debate among fetal medicine specialists about the possibility of pain perception and whether the fetus should be anaesthetised prior to surgical and invasive procedures. Of course the conscious experience of the fetus is unknowable and incommunicable, but the same is true of newborn babies for whom analgesia and anaesthesia is provided. As facial grimacing and aversive responses to noxious stimuli can be seen in premature babies from before 26 weeks gestation, there seems to be prima facie evidence of a primitive form of awareness of pain in the fetus from this gestational age and possibly earlier.

With new advances in medical imaging, including magnetic resonance imaging (MRI), of the fetus and likely developments in electrical and optical fetal monitoring, there is no doubt that the 
scientific trend in fetal behavioural studies will continue. Pilot studies with functional MRI have already suggested that it will become possible to monitor fetal brain responses to stimulation. Similarly the public perception of fetal behaviour from observing antenatal ultrasound examinations will continue to develop. The "convenient fiction" that the fetus is a passive parasite within the mother's body cannot be sustained. Current scientific thinking is to regard the fetus not as a passive tabula rasa, but as a complex responsive organism interacting actively with its intrauterine environment. ${ }^{23}$

\section{Development of fetal medicine as a specialty}

Improved scientific understanding has been paralleled by the rapid development of fetal medicine as a separate discipline. Fetal medicine specialists now employ a range of sophisticated diagnostic techniques to detect fetal illnesses and abnormalities. From the earliest stages of fetal life, ultrasound provides doctors with detailed information about fetal anatomy and functional ability. Doppler ultrasound enables measurement of blood flow in the placenta, heart, and fetal organs, allowing the state of fetal health to be monitored closely, even on a daily basis if necessary. Subtle fetal malformations including missing digits or cleft palate can be diagnosed, as well as minor changes in brain structure or size. Blood samples taken from the umbilical cord enable detailed analysis of blood chemistry and composition and the diagnosis of a range of infections. Soon it may be possible to extend diagnostic possibilities by identification and analysis of fetal cells in the mother's bloodstream. Treatment options are also rapidly expanding. Blood transfusions may be given through the umbilical vessels Drugs designed to cross the placenta may be given to the mother. Tubes can be inserted under ultrasound guidance to drain fluid from kidneys, chest or brain. Fetal surgery to treat major malformations, including lung abnormalities and spina bifida, is now commencing in a few centres worldwide. Treatment both before and after birth is debated and planned in detail with parents, fetal medicine specialists, neonatologists, paediatric surgeons and other specialists. Mothers and their partners are able to observe the detailed fetal images and discuss the options and implications of different procedures. The aim is to provide seamless medical care for the fetus through the intrauterine period and on into the critical first hours and days of birth.

The remarkable growth in antenatal screening for fetal malformations and genetic abnormalities, has led to an increasing "medicalisation" of pregnancy. The new consumerist rhetoric of "providing choices for pregnant women" has become widespread among health professionals. As the number of genetic tests increase, the problems of providing suitable counselling and information are likely to become more intractable. Similarly as the number of disorders that can be detected during pregnancy continues to grow, there is no doubt that more and more couples will face decisions about either terminating affected pregnancies or exploring options of fetal treatment and care. ${ }^{4}$

So do fetal medicine specialists care for one or two patients? Is the fetus merely an organ within the mother's body or does it have a separate medically defined identity? Certainly specialists tend to think of the fetus as a separate individual with its own diagnosis, prognosis, and treatment plan. In addition there appears to be a legal duty of care to this being, in that if the fetus is injured as a result of medical negligence but subsequently survives into postnatal life, it is possible for the child to bring a legal action against the doctors.

There is little doubt that the practice of fetal medicine and surgery will continue to develop with further advances in technology. It is likely that more sophisticated imaging of fetal behaviour and responses will give valuable medical information, allowing fetal wellbeing to be assessed and monitored with greater accuracy. It seems inevitable that the barriers separating the fetus from view and from different possibilities of medical treatment will continue to be progressively overcome by technology.

\section{Development of neonatal intensive care and improved survival of extremely preterm infants}

Along with the development of fetal medicine have been remarkable changes in neonatal intensive care. In 1967 long term survival of preterm babies born before 32 weeks was unusual and 28 weeks seemed an absolute barrier. Since then the prospects for very premature babies have been transformed by the development of specialised intensive care techniques and a huge investment in neonatal research and training. The neonatal intensive care unit where I work is representative of many similar centres. We care for a total of 25-30 babies at any one time and a total of 100 medical, nursing and paramedical staff are available to provide specialised care around the clock. The total cost of care for newborn babies at our hospital runs into several millions of pound per annum and the cost of care for one extremely preterm baby may exceed $£ 50,000$. Survival at 23 and 24 weeks of gestation is now commonplace and occasional survival at 22 weeks and less than $500 \mathrm{~g}$ birthweight has been described.

Many parents, families, and professionals are exposed to the remarkable sight of tiny infants attached to all the paraphernalia of life-support machinery. Parents are encouraged to spend time with their babies, cuddling and talking to them. An attitude of respect for the individuality, significance and value of each baby is cultivated, at whatever stage of gestation and however severe their medical problems. If death becomes inevitable, parents are supported through the grieving process and precious photographs, footprints and personal mementoes are preserved. Charities and individuals donate many thousands of pounds to buy intensive 
care equipment for their local baby unit. The media compete for dramatic pictures and human interest stories. It is sometimes suggested that all this interest in babies is mere anthropomorphic sentimentality, akin to the love and affection which children may lavish on a teddy bear that appears human but is in fact inanimate. But I strongly resist this assertion. Behind the widespread concern, fascination and profound emotional involvement, lies more than mere sentimentality. Nearly all of us share deep-rooted intuitions that the protection, support and nurturing of vulnerable human beings, offering a chance of life to those who cannot fight for themselves, is an essential duty of a civilised society.

At the same time the Human Fertilisation and Embryology Act of 1990 has raised the option of late feticide at any stage up to term, in the case of major fetal malformation. This has led to painfu dilemmas for professionals and parents alike. Medical practice in modern perinatal centres can have a paradoxical element. In one part of the hospital a huge concentration of resources, human expertise, parental concern and professional dedication is devoted to ensuring the survival of babies born as early as $23-24$ weeks. In an adjacent part of the hospital agonised discussions about the possibility of feticide in a much more mature fetus are taking place. Hospital staff may feel deeply uneasy about raising the option of feticide when a major abnormality is detected in the third trimester, but worry about the possibility of legal action if parents are not informed of the option. In my experience some parents express horror when the option of late feticide is explored, and feel a deep sense of personal burden and responsibility for a seemingly impossible decision. In the case of twins where one fetus has a major malformation, there is the legal possibility of delaying feticide until just before delivery in order to minimise risk to the healthy fetus. But this seems to compound the sense of ambiguity and unease amongst professionals and parents. Although in present practice, late feticide is performed relatively rarely, the juxtaposition of this practice with neonatal intensive care units inevitably poses ethical conflicts for health professionals Some would see the involvement of professionals in these apparently contradictory activities as a triumph for maternal autonomy in a pluralistic culture. My own perspective, however, is that the current legal position in Britain, where late feticide can be performed, in theory, at any stage until the moment of delivery, is morally and practically unsustainable. It is remarkable that the current legal position has aroused such little public interest and debate. Surely these are issues which deserve wider discussion and debate.

\section{The perspective of the disability rights movement}

Another major development in the public debate is the growth of the disability rights movement. One eloquent voice is that of Tom Shakespeare, an academic sociologist who happens to be disabled. $\mathrm{He}$ argues that "disabled people are not consulted on matters which affect us: professionals, unrepresentative charities and governments all make decisions about disability, without considering that the best experts on life as a disabled person are disabled people themselves. Politicians, scientists and doctors alike must realise that disabled people do have a particular interest in prenatal testing and should therefore be systematically involved in the public debate". It is clear that many disabled people oppose antenatal screening for disabling conditions because, in Shakespeare's words, "it is very difficult to support a practice which would have prevented one's own existence". In fact many in the disabled rights movement regard antenatal testing for fetal abnormalities as a form of social discrimination against disabled people. They argue that it is disingenuous for scientists and clinicians to claim that the development of antenatal screening is neutral and value free. The option of abortion for a range of genetic and other disorders places a negative value on people with the condition, and implies that it is socially desirable to prevent the birth of certain fetuses. Shakespeare argues that science is a social activity and scientists have to take some responsibility for how scientific information and technology are applied. ${ }^{5}$

Many in the disability rights movement oppose the medical model of disability employed in antenatal testing, with its concern with functional impairment, negative perceptions of the experience of life with disability, and its rhetoric about the "prevention of suffering". They also resist the costbenefit analysis of screening policies with their negative economic valuation of disabled people's lives and the "burden" they represent to society. Instead they argue that "disability" is mainly a social construct, and that the main "suffering" in disabled peoples' lives stems from social discrimination and prejudice, not from functional impairment itself. They argue that antenatal screening for disabling conditions should always be accompanied by input from disabled people themselves, and that abortion legislation should not discriminate against the fetus with a medical impairment. Instead society should concentrate attention and resources on improving practical provision for disabled people. ${ }^{6}$

Of course it can be argued that abortion of a fetus with Down's syndrome, for example, does not imply disrespect for people with Down's syndrome, provided we accept that the fetus is not yet a person. The decision to abort is the decision to prevent a disabled person coming into existence-it has no wider social implications. But this seems disingenuous. There is widespread condemnation of the abortion of female fetuses for "social" reasons in some Asian countries. This practice is seen as enshrining widespread social discrimination against women in these countries. In the same way social approval of abortion of fetuses with Down's syndrome could even be seen as "chromosomalism", enshrining social discrimination against certain forms of DNA. Experience shows that many parents decide to abort an affected fetus, not because of a eugenic unwillingness to bring 
disabled people into the world, but because of the social implications of bringing up a disabled child. A sociological study found that "geneticists, obstetricians and the general public were more blaming towards mothers who gave birth to a child with Down's syndrome, having declined screening, than they were to mothers who had not received screening". ${ }^{7}$ More than one in ten obstetricians in a survey agreed with the statement that "the state should not be expected to pay for the specialised care of a child with a severe handicap where the parents had declined the offer of prenatal diagnosis". ${ }^{8}$ In the words of one disabled person: "To the extent that prenatal interventions implement social prejudices against people with disabilities, they do not expand our reproductive choices. They constrict them."»

The critique provided by the disability rights movement challenges the view that abortion is a purely private or medical matter, the exercise of "procreative autonomy". It argues that a privatised and medicalised approach to abortion enables discriminatory and covertly eugenic attitudes to flourish. Instead we need a more nuanced understanding in which the social implications of antenatal screening and selective abortion are recognised and openly debated. ${ }^{9}$

\section{Social critique of the professional counselling process}

Obstetricians and geneticists generally draw a sharp distinction between giving people information, and letting them make their own decisions on the basis of the information that has been conveyed. The duty of the clinician or counsellor is to convey the medical and scientific information, the facts, in a form that is entirely neutral and value free. The individual patient is then free to make up her own mind about the values she wishes to follows, to exercise individual autonomy free from influences of any kind. This reflects the philosophical facts/values distinction that lies behind the practice of so-called "non-directive counselling". In practice there is strong evidence that many professionals overtly or covertly influence the decisions that parents make. Over one third of a sample of obstetricians in England and Wales said that they generally require a woman to agree to terminate an affected pregnancy before proceeding with prenatal diagnosis. ${ }^{8}$ Several studies have shown that different ways of presenting risks of genetic disease result in different choices by parents. ${ }^{10}$ Similarly the identity of the person who provides counselling (obstetrician, geneticist, paediatrician, independent counsellor) seems to change the likelihood of opting for abortion.

Even when professionals attempt to counsel in a totally non-directive way, they may be aware of grave difficulties. In my experience many patients actively seek directive advice. One of the commonest questions asked of professionals is: "What would you do in my place?"-described as the "terrible question" by an experienced counsellor. ${ }^{11}$

Refusing to give advice or a personal opinion may impede a relationship of trust and openness. In some case a strange struggle ensues with the patient trying to persuade the professional to give a recommendation, and the counsellor trying to "act professionally" and hence not to reveal their own opinions. Faced with this experience, some have concluded that the whole goal of non-directive counselling is flawed. "It is questionable whether non-prescriptive counselling is really possible ... no single story, however balanced can ever be neutral or value free". "So-called non-directive genetic counselling ... . is just as dangerous as paternalistic medicine. The physician is unavoidably engaged in the care of parents and patient, and must work toward disclosing all the information available, including his own opinions." ${ }^{\prime 2}$ Others have argued that people may not always wish to determine what happens to them and that self determination may include the choice to relinquish control to another person. ${ }^{10}$

I have outlined five developments that I believe have irreversibly altered the ethical debate about abortion in Western societies. In place of the old confrontation between a liberal "right to choose" and a fundamentalist "right to life", the modern debate has become more complex, nuanced and difficult. It is only by confronting and analysing these developments in ongoing public debate that a meaningful dialogue can be established.

In the remainder of this paper I will look at the medical duty of care to the fetus and alternatives to medical paternalism.

\section{Medical duty of care to the fetus}

The medical developments described above seem unavoidably to imply that doctors do have some form of professional duty of care to the fetus. The absolutist position that the fetus is owed no duties until the moment of birth seems counterintuitive, illogical and hard to defend. The development of neonatal intensive care is predicated on the belief that even tiny, immature and uniquely vulnerable babies deserve the very best care and that professionals have an ethical duty to act in each baby's own interests even at considerable cost to society. If there is no responsibility to consider fetal interests until delivery, then it must be explained why the moment of birth in itself leads to a transformation of our ethical responsibilities. ${ }^{13}$

Historically the medical professional's duty of care can be seen as one expression of society's concern for the vulnerable. Suppose you opened your door tomorrow morning on the way to work and were confronted with a bundle of blankets on your doorstep, which closer inspection revealed contained an abandoned newborn baby. You are late for work and might miss your train. Nobody else has witnessed the occurrence. It would be perfectly possible to step over the bundle and go on your way. Although you have no legally binding duty to get help for the baby, most of us would perceive a moral duty to protect such a vulnerable life, even if you have to miss your train. The moral commitment that society perceives to protect babies is translated 
into a legally binding duty for doctors. As a paediatrician my duty of care is legally as well as morally binding. The paediatrician's duty of care to protect and care for the extremely preterm baby, born at the hospital or found in the street, is one expression of society's moral commitment to the vulnerable.

Of course the fetus is not simply analogous to baby on a doorstep. If the fetus is to be regarded as a patient then it is in a unique position. Firstly, the fetus is totally dependent on the body of the mother for its moment-by-moment survival. Secondly, absolutely no treatment can be provided to the fetus without in some way breaching the bodily integrity of the mother. So although doctors may perceive a duty to act in the fetus's best interests, in my view they must also respect the bodily integrity of the mother. The mother cannot be considered as merely a biological incubator for the fetus. If she refuses any intervention then a duty of care to the fetus does not override a duty also to respect her integrity. It seems unavoidable therefore that, at times, doctors will confront conflicting duties both to the fetus and to the mother. They must balance a duty to act in the fetus's interests with a duty to respect the mother's integrity. But it seems to me that doctors cannot be expected to maintain a careful neutrality about whether the fetus survives or is destroyed. Health professionals cannot be expected to maintain an artificial equipoise between the options of life and death. Since Hippocrates, the practice of medicine in the West has always enshrined moral commitments that include a primary orientation to protect vulnerable life. This is one reason why raising the option of late feticide can cause such deep ambiguity and sense of ethical conflict amongst professionals.

\section{Alternatives to medical paternalism}

Traditional medical paternalism is based on a parent-child concept of the doctor-patient relationship. The doctor carries authority and wisdom based on professional training and knowledge. The patient should entrust decisions to the doctor who has a duty to act in his or her best interests. In the context of the pregnant mother, medical paternalism combined with a desire to act in the best interests of the fetus, may lead to compulsory detention or treatment of mothers against their will, if they are thought to be acting in a way likely to harm the fetus. In my view this form of medical paternalism is indefensible. It is clearly inappropriate and demeaning to treat a competent adult as though she was a child, however well-meaning and altruistic may be the motivation.

The mirror-image of medical paternalism is an exclusive emphasis on patient autonomy. This is the position which Ronald Dworkin espouses in his influential book Life's Dominion - an Argument about Euthanasia and Abortion. ${ }^{14} \mathrm{He}$ argues that beliefs about the moral status of the fetus and about abortion are quasi-religious and an entirely private concern of each individual. "If the right of privacy means anything it is the right of the individual .. to be free from governmental intrusion into matters so fundamentally affecting a person as the decision whether to bear or beget a child". Dworkin concludes that there should be no legal or medical restriction on the right for individuals to choose an abortion. This leads to what might be described as a client-technician model of professional relationships. The role of the professional is limited to, firstly, providing technical information in a valuefree and non-directive manner and then, secondly, carrying out any medical procedures that are requested according to the autonomous choices of the client. This is the image of medicine as a modern service industry, whose mission statement is "to allow the widest range of informed choice to women and their partners". ${ }^{14}$

Although the client-technician relationship appears to empower pregnant women, in practice there are serious deficiencies in this model. Autonomy is a slippery concept. It may appear to have a clear theoretical meaning to the philosopher, but in my experience it is extraordinarily elusive in the realities of the fetal medicine clinic or intensive care unit. As we have seen, the choices of patients are heavily influenced by the exact way in which information is presented and by whom it is given. Patients are extremely vulnerable when presented with devastating news and may be subject to sudden impulsive reactions, emotional denial, depressive ideation and the effects of illness, fatigue, or medication. In the guise of studied neutrality, professionals are able to exert covert and possibly coercive influence on decisions, by the way that information is presented. Truly informed decision making may require unrealistic amounts of highly technical and complex information to be communicated, understood, and balanced. People vary hugely in their capacity to comprehend the implications of technical information. Many people facing complex and frightening problems seek wise counsel and advice from professionals, not just the communication of value-free facts. The neutraltechnician approach can seem cold and unhelpful as women and their partners struggle with the dilemmas and ethical complexities of modern technological medicine. The truth is that the goal of genuine neutrality in areas as emotive as procreation and abortion is impossible and even inhumane. Whether we hold profound religious convictions or not, we are all coming from somewhere. If postmodernism has taught us anything, it is that there is no Olympian perspective from which these issues can be viewed in benign and omniscient neutrality.

\section{The expert-expert relationship}

In place of both the parent-child and clienttechnician models, I wish to suggest an alternative collaborative model, the expert-expert relationship. It is a partnership between patient and professional based on mutual respect and trust that recognises the unique expertise brought to the collaboration by both sides. The professional should be the expert in the area of diagnostic information, treatment options and possibilities. But the patient 
is also an equally valid expert, with specialist knowledge in her or his own personal concerns, history, family roots, philosophy and way of life. In my view the expertise that the professional brings to the consultation is not merely technical. Part of his or her expertise is in judgment, professional ethics and human wisdom. As we have seen, the practice of medicine enshrines certain moral commitments, including respect, truthfulness and a duty of care to vulnerable individuals. Part of the professional's "expertise" must include the area of personal philosophical or religious convictions. Speaking personally, my own values are strongly influenced by Christian convictions about the unique significance of all human life, including that of the fetus and the premature baby. Other professionals of course may have different personal value systems that will lead them to different conclusions. What is required is openness and transparency about our individual perspectives.

Expert-expert relationships can only flourish in an atmosphere of mutual respect. The professional must respect the areas of expertise of the patien just as the patient must respect the professional's concerns, personal values, and ethical commitments. Instead of the manipulative possibilities of both paternalistic and autonomy-based approaches, expert-expert relationships should be a quest for consensus within a context of openness about personal values and concerns.

Just as professionals must not abuse their position by manipulating or coercing patients against their will, so patients must not coerce professionals to go against their fundamental ethical convictions and professional values. The expert-expert model demands that the professional should have the right of conscientious objection to involvement if personal values are transgressed. This model suggests that if ultimately no consensus can be reached between the parties, then the professional should refer the patient to an alternative expert. In summary I wish to argue that the manipulative and coercive possibilities of professional relationships are minimised, not by the adoption of a mask of apparent neutrality, but by openness and transparency about our personal values and moral perspectives.

\section{Conclusion}

The ethical debate about abortion has been transformed by several irreversible trends in scientific understanding, medical practice, and social critique. In place of the old polarised confrontation between "liberals" and "fundamentalists", the modern debate has become more complex, nuanced and difficult. Old-fashioned medical paternalism is dead but modern autonomy-based concepts of medical relationships are problematic and flawed. Expert-expert relationships provide an alternative collaborative model in which there is a quest for consensus, based on mutual respect and transparency about personal values and concerns.

Fohn Wyatt is Professor of Neonatal Paediatrics and Consultant Neonatal Paediatrician at University College, London.

\section{References}

1 Hepper PG. Fetal psychology: an embryonic science. In: Nijhuis J, ed. Fetal behaviour-developmental and perinatal aspects. Oxford: Oxford University Press 1992:129-56.

2 Glover V, Fisk NM. Fetal pain: implications for research and practice. British Fournal of Obstetrics and Gynaecology 1999;106: $881-6$

3 Teixeira JM, Glover V, Fisk NM. Acute cerebral redistribution in response to invasive procedure in the human fetus. American fournal of Obstetrics and Gynecology 1999;181:1018-25.

4 Green JM, Statham H. Psychosocial aspects of prenatal screening and diagnosis. In: Marteau T, Richards M, eds. The troubled helix. Cambridge: Cambridge University Press, 1996:140-63.

5 Shakespeare T. Choices and rights: eugenics, genetics and disability equality. Disability \& Society 1998;13:665-81.

6 Marteau T, Anionwu E. Evaluating carrier testing: objectives and outcomes. In: Marteau T, Richards M, eds. The Troubled Helix. Cambridge: Cambridge University Press, 1996: 123-39.

7 Marteau T, Drake H. Attributions for disability: the influence of genetic screening. Social Science and Medicine 1995;40:1127-

8 Green JM. Obstetricians' views on prenatal diagnosis and termination of pregnancy: 1980 compared with 1993. British fournal Obstetrics and Gynaecology 1995;102:228-32.

9 McGee G. The perfect baby. Lanham, Maryland: Rowman \& Littlefield, 1997.

10 Shiloh S. Decision making in the context of genetic risk. In: Marteau T, Richards M, eds. The troubled helix. Cambridge: Cambridge University Press, 1996: 82-103.

11 Karp LE. The terrible question. American fournal of Medical Genetics 1983;23:359-62.

12 Shiloh S. Decision making in the context of genetic risk. In: Marteau T, Richards M, eds. The troubled helix. Cambridge: Cambridge University Press, 1996.

13 Chervenak FA, McCullough LB. The fetus as a patient: an essential ethical concept for maternal-fetal medicine. fournal of Maternal Fetal Medicine 1996:5:115-19.

14 Dworkin R. Life's dominion-an argument about euthanasia and abortion. London: Harper Collins, 1995. 